\title{
TRAÇOS DO POSITIVISMO JURÍDICO NO PENSAMENTO HOBBESIANO: UMA LEITURA A PARTIR DE PENSADORES CONTEMPORÂNEOS
}

\author{
Eduardo Cambi ${ }^{1}$ \\ José Eduardo Ribeiro Balera ${ }^{2}$
}

\begin{abstract}
Resumo
O pensamento hobbesiano influenciou de modo substancial a filosofia política e jurídica ao longo da história e ainda se mantém presente, direta ou indiretamente, em diversas abordagens acerca da ordem estatal e sua interação com a sociedade civil. O presente trabalho tem por objetivo delinear uma aproximação do pensamento de Thomas Hobbes à teoria do positivismo jurídico, por meio da análise da obra Leviatã ou Matéria, Forma e Poder de um Estado Eclesiástico e Civil (1651). Inicialmente, serão apresentados elementos basilares da teoria do direito quanto ao positivismo jurídico por meio das considerações do filósofo norteamericano Ronald Dworkin e do pensador italiano Norberto Bobbio. Em seguida, serão examinados aspectos de maior relevância da filosofia política hobbesiana que permitam vislumbrar sua caracterização na qualidade de uma teoria positivista, como a concepção de leis de natureza enquanto preceitos prudenciais, a sujeição à legislação civil e ao poder decisório da autoridade soberana perante a ordem jurídica vigente.
\end{abstract}

Palavras-chave: Thomas Hobbes; Positivismo Jurídico; Sociedade Civil; Autoridade Soberana; Pensadores Contemporâneos.

\section{INTRODUÇÃO}

É inegável a relevância do pensamento do filósofo inglês Thomas Hobbes (15881679) no desenvolvimento de uma teoria política e do direito acerca das origens do Estado e da autoridade soberana e que mantém sua influência nas reflexões e discussões teóricas da atualidade. Em sua principal obra, intitulada de Leviatã ou Matéria, Forma e Poder de um Estado Eclesiástico e Civil, que será referenciada ao longo do trabalho como Leviatã, o pensador concebe uma tese marcada pela racionalidade que influenciou diversas linhas do

\footnotetext{
${ }^{1}$ Promotor de Justica no Paraná. Assessor da Procuradoria-Geral de Justiça. Coordenador do Centro de Estudos e Aperfeiçoamento Funcional do MPPR. Professor da Universidade Estadual do Norte do Paraná (UENP) e da Universidade Paranaense (UNIPAR). Pós-doutor em Direito pela Università degli Studi di Pavia. Doutor e mestre em Direito pela Universidade Federal do Paraná (UFPR). Universidade Estadual do Norte do Paraná - UENP, Paraná - Brasil. E-mail: eduardocambi@hotmail.com

${ }^{2}$ Mestre em Filosofia Contemporânea pela Universidade Estadual de Londrina (UEL). Mestre em Ciência Jurídica pela Universidade Estadual do Norte do Paraná (UENP). Especialista em Direito Público pela Faculdade Damásio de Jesus. Especialista em Filosofia e Teoria do Direito pela Pontifícia Universidade Católica de Minas Gerais (PUC/MG). Especialista em Direito do Estado com ênfase em Direito Administrativo pela Universidade Estadual de Londrina (UEL). Professor da UNIFAMMA Centro Universitário e advogado da Câmara Municipal de Maringá. Universidade Estadual do Norte do Paraná UENP, Paraná - Brasil. E-mail: j.ribeirobalera@hotmail.com
} 
pensamento, seja de cunho jusnaturalista, seja quanto aos adeptos do positivismo.

A presente investigação tem por finalidade delinear traços da teoria hobbesiana que expressam maior proximidade com as bases do positivismo jurídico. Para tanto, foi considerada a argumentação do autor inglês expressa, principalmente, por meio da obra Leviatã, embora existam outras produções de relevância, como Do Cidadão e Os Elementos da lei natural e politica.

Não se almeja com essa análise resgatar a discussão acerca das pretensões hobbesianas sob os fundamentos teológicos necessários ou não para sua filosofia política, mas explicitar traços de sua teoria que se compatibilizam a elementos estruturais ainda observados no positivismo jurídico contemporâneo, como de Herbert L. A. Hart.

Para tanto, foram considerados aspectos basilares apresentados por Ronald Dworkin, pensador norte-americano que dedicou parte substancial de sua produção acadêmica à crítica ao positivismo jurídico de John Austin e Herbert L. A. Hart. Também foram ponderadas as reflexões trazidas por Norberto Bobbio, pensador italiano nascido em Turim, o qual concentrou uma parte importante de seus estudos na doutrina positivista e teceu análises da tese hobbesiana.

Nesse estudo, examinam-se institutos essenciais à teoria de Thomas Hobbes, como a ideia de leis de natureza. Assim, visou-se compreender a melhor interpretação para tal conceito, seja enquanto preceitos prudenciais ou obrigações morais.

Em seguida, definida a concepção preponderante a ser considerada ao longo do trabalho, examinou-se a abordagem de Hobbes acerca das leis positivas e sua força obrigatória perante os súditos, enquanto expressão de comando emanado da autoridade soberana com o pacto civil.

Por conseguinte, perquiriu-se o dever de obediência existente na tese do pensador inglês, bem como a atuação da autoridade soberana e seu poder decisório, frente às leis naturais e na ocasião de ausência de abrangência normativa contundente das leis positivas.

\section{APORTES DA TEORIA DO DIREITO ACERCA DO POSITIVISMO JURÍDICO}

Para o devido exame das características do positivismo jurídico presentes na obra Leviatã de Thomas Hobbes, é necessário um breve resgate da teoria do direito. Nos estudos da teoria e da filosofia do direito na modernidade, tem-se destacado o papel de Ronald Dworkin, crítico das correntes do positivismo jurídico, e de Norberto Bobbio, jurista italiano 
adepto de uma teoria da norma e do ordenamento claramente positivista e que estabeleceu estudos também entre a filosofia e a teoria política.

Nas obras Levando os Direitos a Sério e O Império do Direito, Dworkin traça termos gerais e de ordem estrutural pertencentes ao positivismo, pois ele expõe que para tal concepção teórica: (i) o direito é compreendido como um agrupamento de regras, sendo estas entendidas como ordens emanadas por uma autoridade e que visam definir as condutas a serem penalizadas, coibidas ou tolhidas pela atuação do poder público - realizando a distinção entre normas válidas e espúrias (as quais erroneamente são confundidas com regras jurídicas) que a comunidade segue, mas que não se faz cumprir pelo poder público; (ii) esse conjunto de regras pode ser complementado ou servir na orientação para a criação de uma nova regra, caso a controvérsia suscitada não esteja abrangida por uma regra preexistente, tornando-se necessário o exercício pela autoridade pública do seu discernimento, dando abertura à discricionariedade; (iii) é pelo enquadramento a determinada regra válida que surge a obrigação jurídica, para que o indivíduo passe a agir ou se abstenha, pois na ausência de regra não se tem obrigação jurídica.

Em sua última obra, Justice for Hedgehogs, o pensador norte-americano resgata que o positivismo assegura uma completa independência entre o sistema do direito e da moral, pois o direito dependeria apenas de questões históricas de fato, quanto ao costume e às práticas aceitas como direito por determinada comunidade. Logo, se uma lei injusta for proclamada, caso atenda a essa avaliação e seja aceita por uma comunidade como lei, inclusive, tendo sido aprovada pelo legislativo, sem perder de vista que os juízes estão de acordo que o poder legislativo é o supremo legislador, então a lei injusta realmente é considerada direito (DWORKIN, 2011, p. 401).

Não obstante, o positivismo jurídico também pode ser observado por outras perspectivas. Para o pensador Norberto Bobbio (1995, p. 223), é importante ter a clara distinção entre teoria e ideologia. A teoria é um posicionamento tão somente "cognoscitivo" assumido pelo indivíduo perante a realidade, almejando instruir aos outros acerca da realidade a partir de um conjunto de juízos de fato. Já a ideologia é a postura "avaliativa” do indivíduo perante essa realidade, constituída por um complexo de juízos de valores sobre a mesma, sendo que esse conjunto está fundamentado no "sistema de valores" admitidos pelo indivíduo. Essa distinção permite ressaltar que na teoria pode-se dizer em termos de "verdadeiro" ou "falso", enquanto que na ideologia isso não poderia ser feito, mas tão somente identificá-la como "conservadora" ou "progressista" de acordo com a avaliação que é realizada sobre a 
realidade, seja uma análise positiva, que busca "conservá-la", ou uma avaliação negativa, que propõe como influir e mudá-la.

O positivismo, além de sua perspectiva teórica que visa a "pureza" e a visão descritiva do direito, pode ser observado como uma expressão ideológica. Mesmo a teoria de John Austin, que é evidentemente teórica, possui uma ideologia mascarada. Assim, Austin, ao descrever o direito como um comando definido por um soberano, inevitavelmente, constitui de modo implícito um juízo de valor que dá preferência ao direito como um comando e não como mera "regra consuetudinária". Esse positivismo ético ou de caráter ideológico pode se manifestar por duas posturas bem definidas: (i) o positivismo extremista, em que o valor trazido é a obediência incondicional à lei, não apenas como obrigação jurídica, mas até mesmo moral; (ii) o positivismo moderado é uma faceta do chamado positivismo ético, no qual o valor do direito, que independe de seu conteúdo, não está na validade e na simples obediência absoluta à lei e ao seu comando, mas na realização de um fim ou "valor instrumental", no caso, o perfazimento da ordem (BOBBIO, 1995, p. 223-232).

Para o positivismo jurídico, não existe qualquer outro direito que não seja o de ordem positiva. Logo, há um distanciamento da teoria do direito natural, que alguns autores ${ }^{3}$ observam na obra hobbesiana, pois o jusnaturalismo supõe a existência de um direito transcendente e preexistente em relação ao direito positivo, seja em decorrência da razão, da natureza ou do divino, como a única ordem reguladora com validade universal. Para o jusnaturalismo, o direito natural sempre deverá prevalecer em relação ao direito positivo, pois o ser humano pode até se equivocar nas disposições do direito positivo, mas a lei natural não (MARCONE, 2005, P. 123).

É com base nesses sinais teóricos distintivos que se vislumbra a compreensão do pensamento de Thomas Hobbes e a identificação de indícios caracterizadores de uma teoria propensa e originária do positivismo jurídico, bem como a interpretação apropriada acerca de marcas teóricas de sua filosofia política que ora se aproximam ou se afastam da teoria jusnaturalista.

\section{HOBBES E O LEVIATÃ: A POSSIBILIDADE DE UM POSITIVISMO JURÍDICO}

\footnotetext{
${ }^{3}$ Autores como José Nedel e, em algum sentido, Norberto Bobbio. Para este último, a questão se demonstra mais atenuada, pois Hobbes seria pertencente ao jusnaturalismo como também originário de uma teoria positivista do direito.
} 
É inegável que a filosofia política de Thomas Hobbes é referência fundamental no pensamento político e jurídico moderno, tanto pela coerência lógica como pela fundamentação legitimadora de uma teoria do Estado soberano. Independentemente da discussão acerca do elemento teológico ou não presente em sua obra, que não é o objeto deste artigo, o pensador inglês estabelece uma estratégia argumentativa à construção de uma teoria contratualista justificadora das origens e da necessidade do Estado, bem como a figura da autoridade soberana, manifestada por um corpo de membros ou por um único indivíduo.

Para José Nedel (1993, p. 433-437), Thomas Hobbes seria um adepto do jusnaturalismo, pois (i) insinuaria a retirada do conteúdo do direito positivo do direito natural, conferindo validade jurídica a este ou mesmo (ii) retiraria da lei natural não propriamente seu conteúdo, mas o fundamento de validade da lei positiva. Em seu estudo, José Nedel defende que o projeto jusnaturalista hobbesiano teria sua coerência na última hipótese, garantindo a ideia de obediência às leis tão essencial em seu sistema. Logo, o dever de obediência passaria a ser sua obrigação natural (ou moral) justificadora do Estado Soberano. Apesar disso, ainda José Nedel alega que as demais leis naturais seriam "varridas" pela ideia de soberania.

Apesar da interpretação apresentada por José Nedel, é possível a averiguação, no pensamento de Hobbes, de inúmeras pontualidades que o afastariam dessa simplista designação jusnaturalista, mas originária de uma teoria do direito substancialmente positivista. É notável na obra Leviatã ou Matéria, Forma e Poder de um Estado Eclesiástico e Civil traços elementares da teoria do positivismo jurídico ou que, ao menos, influenciaram autores posteriores, como John Austin, na composição e fundamentação de uma teoria positivista do direito com rigor lógico e científico.

É nesse cenário que se torna essencial a avaliação de diferentes dimensões da obra de Thomas Hobbes, iniciando-se pela compreensão do papel da ideia de leis de natureza e sua caracterização enquanto preceitos prudenciais ou obrigações morais, para posterior compreensão das sujeições às denominadas leis civis ou positivas, bem como à autoridade soberana e sua atuação decisória.

\subsection{AS LEIS DE NATUREZA: ENTRE A OBRIGAÇÃO MORAL E OS PRECEITOS PRUDENCIAIS}

Antes de se adentrar nos traços mais característicos do positivismo presente no pensamento filosófico de Hobbes, como a sujeição intangível às leis civis emanadas pela autoridade soberana, é preciso entender a faceta de sua teoria no que se refere às leis de natureza, que são consideradas como substrato caracterizador de um jusnaturalismo por 
autores da filosofia política, como Norberto Bobbio. Para o pensador italiano, Hobbes seria adepto, de fato, de uma teoria fundada no direito natural; porém, seria também defensor, de direito, de uma teoria do positivismo jurídico (BOBBIO, 1991, p. 101).

Para a devida caracterização da teoria hobbesiana, seja como uma concepção jusnaturalista ou adepta originária de uma doutrina do positivismo jurídico, é imprescindível examinar qual a melhor interpretação das leis naturais, tanto como preceitos prudenciais quanto como disposições morais obrigacionais.

Antes de tudo, cumpre ressaltar que a lei de natureza é, nas palavras de Hobbes (1979, p. 78), “um preceito ou regra geral, estabelecido pela razão, mediante o qual se proíbe a um homem fazer tudo o que possa destruir sua vida ou privá-lo dos meios necessários para preservá-la, ou omitir aquilo que pense poder contribuir melhor para preservá-la”. Em síntese, as leis seriam teoremas da racionalidade que avaliam a ordem de consequências para determinado fim, de maneira que a utilização do termo "proibir" e "privar" não podem ser interpretados em seu caráter mais estrito de observância.

Não se pode alegar uma suposta irracionalidade no estado de natureza, uma vez que as disposições manifestadas pela lei de natureza são preceitos advindos de uma racionalidade que almeja a autoconservação do homem. Em outros termos, as leis de natureza seriam prescrições advindas da operacionalização racional com a constatação de consequências e possibilidades de melhor manutenção da própria integridade, diante de um cenário de insegurança, mas não necessariamente a descoberta de uma verdade.

Ao se considerar as leis de natureza como preceitos prudenciais e não preceitos normativos morais obrigatórios ao ser humano, permite-se entender que Hobbes prescreve comportamentos adequados à promoção e ao benefício próprio do indivíduo e não como disposições obrigacionais que possam ser qualificadas como certas e erradas. O capítulo XIII do Leviatã evidencia que no estado de natureza não há espaço para o bem e o mal, pois há um vazio moral, regido pela força, pela fraude e pelo interesse de autopreservação.

Logo, as prescrições advindas da lei de natureza não são imperativos ou proibições de ações que se justificam enquanto morais ou não, mas recomendações racionais a serviço e na promoção do autointeresse do ser humano. Ainda que tudo seja permitido no estado de natureza em prol da autopreservação, Hobbes defende que a crueldade e a embriaguez são contrárias a lei de natureza e não seriam admitidas. Nesse momento, não se trata de uma restrição estrita de cunho moral, mas um novo preceito prudencial, uma vez que ambas as atitudes se afastam da finalidade da paz, da manutenção da própria sobrevivência e são instigadores do dissenso e do conflito. 
Hobbes parece confirmar a compreensão prudencial das leis de natureza diante da impropriedade terminológica da utilização da palavra "lei". Na estrita compreensão do pensador inglês:

A estes ditames da razão os homens costumam dar o nome de leis, mas impropriamente. Pois eles são apenas conclusões ou teoremas relativos ao que contribui para a conservação e defesa de cada um. Ao passo que a lei, em sentido próprio, é a palavra daquele que tem direito de mando sobre outros (HOBBES, 1979, p. 95).

Portanto, enquanto ditames da razão, as leis de natureza não detêm uma autoridade para imposição de seu cumprimento e obrigação de determinada ação, não possuem vigência e "direito de mando" como as leis positivas, sendo meros aconselhamentos pela relação racional de meios e da finalidade visada.

Na continuação do excerto acima apresentado, Hobbes (1979, p. 95) se manifesta de tal modo que a interpretação moral das leis de natureza é aparentemente viabilizada, pois ressalta que "se considerarmos os mesmos teoremas como transmitidos pela palavra de Deus, que tem direito de mando sobre todas as coisas, nesse caso serão propriamente chamados leis".

A sustentação de uma interpretação moral das leis de natureza conduz a perspectiva de que seria possível a observância de um modelo de comportamento a ser sempre considerado virtuoso e apropriado à efetivação de uma ideia de correção ou de bom. Porém, o próprio filósofo inglês reconhece que não é cabível no estado de natureza a caracterização da conduta como justa ou injusta ou mesmo certa ou errada, porque somente com a instituição do Estado, com o pacto civil, que a ideia de justiça, enquanto cumprimento da lei e dos pactos, passaria a ter significativa relevância.

No capítulo XXVI da obra Leviatã, o caráter prudencial das leis de natureza é reforçado diante de uma racionalidade que visa à paz e a autopreservação. Nas palavras do pensador:

Porque as leis de natureza, que consistem na equidade, na justiça, na gratidão e outras virtudes morais destas dependentes, na condição de simples natureza [...] não são propriamente leis, mas qualidades que predispõem os homens para a paz e a obediência (HOBBES, 1979, p. 162).

Dessa maneira, enquanto qualidades para a predisposição em alcançar determinada finalidade, as leis de natureza não possuem força obrigacional, mas são meras recomendações diante dos ditames da racionalidade. Para Stephen Finn (2010, p. 108), é possível a defesa da 
concepção prudencial da lei de natureza, uma vez que é "uma regra descoberta pela reflexão racional que promove os autointeresses dos indivíduos".

As leis de natureza "obrigam apenas em consciência" (BOBBIO, 1991, p. 110), pois somente as leis positivas possuem legitimidade e demandam incondicional obediência. Mesmo no capítulo XV do Leviatã, ao dispor acerca de outras leis de natureza, Hobbes expressa preceitos imprescindíveis à manutenção da paz ou ao seu restabelecimento caso seja infringida.

Para Hobbes, as leis de natureza inspiram ao desejo de que sejam cumpridas, pois obrigam no foro interno, mas esse desejo de que sejam colocadas em prática nem sempre se tornam obrigações no plano externo. Afinal, não há dúvidas de que todas as leis que se impõem in foro interno podem ser descumpridas, "não apenas por um fato contrário à lei, mas também por um fato conforme a ela, no caso de seu autor considerá-lo contrário. Pois embora neste caso sua ação seja conforme à lei, sua intenção é contrária à lei, o que constitui uma violação quando a obrigação é in foro interno" (HOBBES, 1979, p. 94).

Com a qualificação das leis de natureza como preceitos prudenciais, Hobbes se afasta das concepções mais tradicionais do jusnaturalismo e fortalece os alicerces para a concretização de um positivismo jurídico em sua obra.

Como ressalta Bobbio (1991, p. 105), enquanto a lei natural, em sua concepção tradicional, prescreve o que é bom ou mau por si só, na concepção hobbesiana, a lei natural expressa o que é bom ou mau com referência a determinado fim, obtido por meio da razão, conduzindo, assim, o indivíduo à autoconservação e à manutenção de sua defesa. Em outras palavras, Hobbes adotaria uma concepção de lei natural de perspectiva utilitarista, uma vez que almeja um fim determinado a conservação do homem, que seria a paz, enquanto a finalidade das prescrições para outros jusnaturalistas seria o bem, em sentido moral, independentemente das vantagens ou desvantagens que possam produzir.

Ao estabelecer a lei de natureza como preceito que indica condutas e ações que visam à autopreservação e à finalidade da obtenção da paz, Hobbes passa a delinear um primeiro pressuposto para uma futura teoria positivista que seria a constituição de uma sociedade civil e do ente estatal por meio da transferência de livre atuação dos indivíduos ao Estado Soberano, pois este passa a ser o meio eficaz para a obtenção da paz, uma vez que a autoridade soberana irá dispor as condutas permitidas e proibidas, com o monopólio coercitivo para seu cumprimento. Na compreensão de Bobbio (1991, p. 107): 
[...] a lei natural afirma que, para alcançar o fim prescrito pela própria lei natural, o homem deve se deixar governar pelas leis positivas. Trata-se de uma declaração de impotência por parte de leis naturais: e, com efeito, para não falar de outras coisas, as leis naturais obrigam apenas em consciência, isto é, não obrigam absolutamente, dada a concepção utilitarista de Hobbes.

Para o pensamento hobbesiano, são as obrigações instituídas com a sociedade civil que possuem um valor incondicional de obediência, independentemente de qualquer avaliação de seu conteúdo, simplesmente pelo fato de terem sido emanadas do soberano com tal poder de comando.

Entretanto, parece inegável que Hobbes admite a lei natural como fundamento ao direito positivo. Em uma relação paralela a outro pensador do positivismo jurídico, enquanto Hans Kelsen estabelece uma relação escalonada que retira seu fundamento de uma norma hipotética fundamental, Hobbes não cria uma hipótese normativa, mas defende o valor normativo da lei natural de caráter inaugural para fundamentar a constituição do Estado e de todo o sistema jurídico vigente na sociedade civil. Esse aspecto o aproxima do jusnaturalismo e está em conformidade à compreensão interpretativa de Norberto Bobbio (1991).

Ainda que também seja evidente a relevância das leis de natureza na construção lógica da teoria hobbesiana e da indubitável caracterização das leis de natureza como preceitos prudenciais, pode-se entender que a fundamentação na lei de natureza para a realização do pacto social representa uma argumentação lógica do pensador, sendo que o contrato social seria o elemento hipotético originário e legitimador da ordem jurídica positiva, a exemplo da teoria do poder constituinte originário moderno.

O contrato social e a consequente legitimação do Estado Soberano mais se aproximam de uma construção lógica do que propriamente de uma concepção jusnaturalista tradicional que garanta a total supremacia das leis de natureza. Isso porque Hobbes ainda mantém um caráter de sujeição à ordem jurídica positiva, como se observará posteriormente, que constituí indício distintivo à origem de uma teoria positivista. Seu contratualismo político expressa elementos justificadores da autoridade legitimada e com poder pela edição da lei positiva, assemelhando-se funcionalmente à ideia de regras secundárias ${ }^{4}$ de Hart em seu positivismo jurídico.

\footnotetext{
${ }^{4}$ As regras secundárias podem ser de reconhecimento, de alteração e de julgamento. As regras de reconhecimento permitem a identificação das normas primárias (estas são determinações acerca de condutas omissivas ou comissivas de forma independente à vontade e ao desejo dos indivíduos), de maneira a estabelecer o critério de validade das normas; as normas de alteração indicam a autoridade (seja indivídual ou do órgão legitimado) para a inclusão de nova regra, alteração ou supressão de regra jurídica vigente; as regras de julgamento definem as autoridades responsáveis pela apreciação de um fato em
} 


\subsection{A LEI CIVIL, A LEGALIDADE E A FORÇA OBRIGACIONAL}

O Leviatã e a defesa da submissão incontestável ao direito positivo afastam Hobbes da tradicional teoria jusnaturalista, pois, para esta corrente, a lei positiva tem seu fundamento no direito natural de tal maneira que só pode ser considerada obrigatória na medida em que se encontre conforme a mesma. O pensamento hobbesiano também traz elementos para a fundamentação da ordem do direito positivo no direito natural, como foi disposto anteriormente, inclusive enquanto justificativa para a constituição de um estado absoluto. Entretanto, o filósofo inglês estabelece outra relação entre lei natural e lei positiva, uma vez que aquela só passa a ser obrigatória a partir do momento em que se encontra positivada.

Diferentemente da lei de natureza que é ditame da racionalidade, a lei civil não é mera recomendação e não emana de qualquer um, mas é dirigida a alguém que antecipadamente reconhece seu dever de obediência. A lei civil, nas estritas palavras de Hobbes (1979, p. 161), “é, para todo súdito, constituída por aquelas regras que o Estado the impõe, oralmente ou por escrito, ou por outro sinal suficiente de sua vontade, para usar como critério de distinção entre o bem e o mal; isto é, do que é contrário ou não é contrário à regra". Essa definição conduz a um conceito de direito enquanto conjunto ou agrupamento de regras definidoras de condutas admitidas ou coibidas pelo poder público, alicerce à definição de uma teoria positivista jurídica.

Ainda que seja uma definição simplista e autoevidente, ela orienta a uma submissão a autoridade estatal. No capítulo XXVI do Leviatã, Hobbes (1979, p. 161) ainda complementa: "as leis são as regras do justo e do injusto, não havendo nada que seja considerado injusto e não seja contrário a alguma lei. E igualmente que ninguém pode fazer leis a não ser o Estado, pois nossa sujeição é unicamente para com o Estado". Tais excertos corroboram a supremacia da legalidade como critério definidor de avaliação das condutas, independentemente de preceitos de ordem moral.

Portanto, enquanto expressão da autoridade com poder legítimo de comando para tal definição obrigacional, seja como dever ou como proibição, o direito positivo é parâmetro definidor e autossuficiente para a caracterização do justo e do injusto, afastando a normatividade de outras disposições, como de cunho eclesiástico ou de comunidades e instituições menores (BOBBIO, 1991, p. 103).

concreto frente a possibilidade de violação de uma regra primária. Cf. HART, Herbert L. A. O conceito de Direito. Lisboa: Fundação Calouste Gulbenkian, 2001. 
Porém, o pensamento hobbesiano não abandona por completo as disposições inicialmente apresentadas quanto às leis de natureza pelo simples fato de reconhecer o preceito da legalidade. Passa a ser estabelecida uma relação distinta entre direito positivo e lei de natureza, pois o pensamento hobbesiano defende que a "lei de natureza e a lei civil contêm-se uma à outra e são de idêntica extensão" e complementa que a "lei civil e a lei natural não são diferentes espécies, mas diferentes partes da lei, uma das quais é escrita e se chama civil, e a outra não é escrita e se chama natural" (HOBBES, 1979, p. 162-163).

Ao enfatizar essa relação, Hobbes permite a compreensão de que a lei positiva é a única a constituir a obrigação jurídica de atuação ou omissão; porém, a lei de natureza, enquanto teorema racional que visa determinada finalidade, é preceito material, ou seja, a lei natural é o conteúdo que passa a ser exigível pela autoridade da lei positiva e, por isso, de iguais extensões.

Essa correlação parece minimizar a importância da lei natural à definição do conteúdo da lei positiva, agravada pela falta de vínculo obrigacional daquela. Todavia, Hobbes parece minimizar ainda mais o papel da lei de natureza na obra Do Cidadão e acentuar o caráter do positivismo jurídico, pois ainda que a lei de natureza disponha algo como sendo errado, a exemplo do roubo, será a lei positiva expedida pela autoridade soberana a definidora do conteúdo do roubo.

Logo, o conteúdo da lei natural se esvazia perante a relevância da lei positiva. É certo que o roubo, o assassinato e todas as injúrias são reconhecidamente proibidos pela lei de natureza; contudo, são as leis civis que determinam o que são essas condutas. Por exemplo, roubar não seria somente expropriar alguém de bens que possua, mas somente de suas coisas móveis, mediante grave ameaça ou violência, ou, depois de havê-la, por qualquer meio, reduzido à impossibilidade de resistência (CP, art. 157, caput). No entanto, é a lei civil que determinará o que são coisas móveis de uma ou outra pessoa. Não é qualquer prática de homicídio configuradora de assassinato, uma vez que esta última conduta é tão somente aquela que a lei civil proíba. O mesmo se aplica na caracterização da injúria, enquanto quebra de promessa, pois só será considerada promessa aquele pacto em conformidade com a lei; caso contrário, não há como se falar em tal ofensa à ordem jurídica (HOBBES, 2002, p. 112).

Cumpre lembrar que, mesmo que as leis de natureza sejam consideradas prescrições morais, o marcante viés do positivismo jurídico ainda se manteria no pensamento de Thomas Hobbes, porque a moralidade e o direito são sistemas distintos, mas há autores que reconhecem que a moralidade acaba por influenciar historicamente no conteúdo da lei. Como destaca Baxter (2010, p. 858, tradução livre) no debate acerca do positivismo: 
[...] positivista como H. L. A. Hart tem reconhecido que o conteúdo da moralidade historicamente tem influenciado o conteúdo da lei. Em vez disso, Dworkin parece dar o sentido que, para o positivismo, a moralidade tem no máximo um papel contingente na especificação das condições de verdade das proposições jurídicas. Moralidade, igualmente para o positivismo "inclusivo", é relevante na determinação do direito num dado ponto apenas se a regra social, como regra de reconhecimento de Hart, é fundamentalmente especificada. Esta regra de reconhecimento é uma regra social, aceita "por uma questão de costume e prática".

A ideia dworkiana compreende o jusnaturalismo como uma concepção que vê a moralidade como um “veto sobre a lei”, no sentido de que, se uma lei é moralmente ultrajante, não pode ser tida como válida (BAXTER, 2010, p. 858). Nesse sentido, trazida por teóricos contemporâneos do direito, como Ronald Dworkin, a tese hobbesiana estaria mais próxima da construção de um positivismo do que propriamente de uma tese jusnaturalista.

Norberto Bobbio (1991) recorda que o pensamento hobbesiano manifesta uma concepção de justiça formal, pois a justiça passa a cingir-se no cumprimento de obrigações e, no caso do cidadão defronte ao estado, na sua obrigação de obediência à lei, independentemente de qualquer que seja seu conteúdo. Essa ideia de justiça não existe no estado de natureza, uma vez que não há qualquer pacto instituidor de um vínculo obrigacional entre as pessoas. Nas palavras do pensador italiano:

Uma vez constituído o estado civil, através do pacto intersubjetivo de união, ação justa é aquela que se dá conforme a lei que deriva a vontade do soberano, expressa com base nas condições estipuladas no pacto social, enquanto injusta é aquela não conforme. Trata-se, como todos podem ver, de uma clara formulação da concepção legalista da justiça, que é um aspecto da concepção formal da justiça (BOBBIO, 1991, p. 103).

Logo, a própria ideia de justiça passa a ficar adstrita à concepção de legalidade, enquanto ordem emanada do poder legítimo de determinada autoridade soberana, de forma a manifestar a tradicional compreensão positivista em que as disposições do direito positivo passam a ser o critério definidor do justo e do injusto, ignorando-se qualquer outra expressão, como a ideia de direito natural, no processo de avaliação e direcionamento das condutas, seja para aprová-las, seja para desaprová-las.

\subsection{A AUTORIDADE SOBERANA E SUA ATUAÇÃo DECISÓRIA}

As reformulações políticas de Hobbes viabilizam a construção de um conceito de estado caracterizado pela monopolização do direito e da força, elidindo qualquer outra fonte 
normativa que não seja a lei, enquanto vontade do soberano reconhecido pelo pacto civil, afastando-se de ordenamentos não jurídicos de ordem comunitária, religiosa, entre outras. Afinal, "um poder estatal não poderá ser considerado absoluto - isto é, sem limites, se se reconhecer a existência e a legitimidade de um conjunto de leis, como é precisamente o caso das leis naturais, superiores por sua íntima constituição às leis positivas, e às quais estas devam conformar-se" (BOBBIO, 1991, p. 104).

O papel do Estado Soberano, como ressalta John Rawls (2012, p. 81), é garantir a estabilidade em um estado de sociedade civil em que sejam mantidas circunstâncias de normalidade e de fidelidade às leis da natureza, por ser marcado pela insegurança e pela racionalidade em busca da autopreservação. Sem um poder civil que as garanta, as promessas realizadas não são pactos. No estado de natureza, não há garantia do cumprimento das promessas; logo, aquele que vier a cumprir primeiro estará beneficiando o inimigo e traindo a si mesmo, agindo contra sua autopreservação e se colocando em vulnerabilidade.

Com a existência do Soberano, a irracionalidade da conduta perante o estado de natureza, de cumprir as leis como a obediência aos pactos, passa a ser racional. Isso não significa que o Soberano irá alterar ou corrigir o caráter dos indivíduos, mas alterará as condições fundamentais que viabilizam o pensar racional. Assim, torna-se possível a estabilidade de um sistema em que todos atuem de modo que se produzam vantagens mútuas (RAWLS, 2012, p. 86-87).

A autoridade soberana de um Estado, seja ela uma assembleia ou um único indivíduo, não se sujeita às leis civis, uma vez que tem o poder de fazer as leis e revogá-las quando necessário, ainda que tenha de visá-las em sua atuação. Afinal, "a ninguém é possível estar obrigado perante si mesmo, pois quem pode obrigar pode libertar, portanto quem está obrigado apenas perante si mesmo não está obrigado" (HOBBES, 1979, p. 162).

As leis definidas pelo soberano não podem ser consideradas injustas, pois este poder foi assegurado e admitido por todos com a realização do contrato social. Porém, seria contraditório se Hobbes defendesse que o súdito tivesse confiado ao soberano o direito de causar prejuízos a si próprio ou colocar em risco a autopreservação. Por tal motivo, Hobbes $(1979$, p. 133) defende que "se alguém for interrogado pelo soberano ou por sua autoridade, relativamente a um crime que cometeu, não é obrigado (a não ser que receba garantia de perdão) a confessá-lo, porque ninguém [...] pode ser obrigado por um pacto a recusar-se a si próprio".

É inegável o dever de obediência do súdito ao soberano, pois este é a autoridade mantenedora da estabilidade da sociedade civil, em contraposição a insegurança do estado de 
natureza. No entanto, é reconhecido também como exceção a esse dever de sujeição e obediência a partir do momento em que o soberano coloca em risco a vida do súdito, pois a própria finalidade da constituição de um Estado Soberano foi a superação da guerra de todos contra todos e as ameaças constantes do estado de natureza. A partir do instante em que o Estado Soberano ameaça a vida de seu súdito, este não está mais em consonância ao pacto celebrado. Ainda que se defenda o direito do soberano de condenar seu súdito e ordenar sua execução, é também evidente o direito do súdito de ignorar o dever de obediência e salvarse, mesmo que pela força, contra tal punição (BOBBIO, 1991, p. 122-123).

Contudo, cumpre lembrar que a tese hobbesiana reconhece que a conduta do soberano poderá ser iníqua, pois a ideia de justiça está atrelada ao cumprimento de pactos, enquanto a iniquidade, a ofensa às leis de natureza. Desse modo, uma ação injusta transgride a lei positiva, enquanto uma ação iníqua viola as leis de natureza.

Para Rawls (2012, p. 93), quando determinadas leis não são consideradas boas significa que não "garantem condições fundamentais que possibilitam que todos considerem razoável ou racional a fidelidade às leis da natureza". Isto posto, é possível que o Soberano venha a decretar ou emanar más leis, o que será ou não definido conforme os interesses racionais de seus súditos. Ainda assim, é inegável que o filósofo inglês defende que viver sob leis más não é tão ruim se comparado ao estado de guerra com as inseguranças e instabilidades pertencentes ao estado de natureza.

Uma vez conhecidos os aspectos basilares quanto ao papel da autoridade soberana na teoria hobbesiana, surge uma problemática tratada por teóricos do direito e que evidenciam a abordagem assumida segundo bases positivistas ou não. Caso seja observada uma ausência normativa no ordenamento, em outros termos, a existência de uma lacuna legal, quais seriam os limites de atuação da autoridade soberana?

Para autores positivistas, como Herbert L. A. Hart (2001, p. 144-145), considerando que as disposições legais são gerais, a autoridade deve atuar e exercer seu poder de discricionariedade, pois "não há possibilidade de tratar as questões suscitadas pelos variados casos, como se houvesse uma única resposta correta a descobrir, distinta de uma resposta que seja um compromisso razoável entre muitos interesses conflitantes".

No entendimento de John Austin, a obrigação jurídica decorreria sempre da submissão à determinada regra que expressa a ordem abstrata e de caráter geral de um soberano. A não observância da regra e, por consequência, da ordem emanada, torna aplicável uma penalidade, estando os juízes "habilitados" a criarem novas regas para hipóteses inéditas que venham a surgir. Vale destacar que, ainda nesses casos inéditos, o soberano poderia 
anular as novas formulações ou tacitamente confirmá-las (DWORKIN, 2007, p. 41-42).

O comando seria a própria expressão de um desejo do soberano; porém, distinguese das outras expressões de vontade, porque o não cumprimento torna passível de um mal, isto é, a aplicação de uma sanção. O indivíduo está vinculado ou obrigado a esse comando, tornando-se um dever obedecê-lo. O dever e o comando são termos correlatos para Austin e o direito caracteriza-se, em certo grau, pela coercibilidade (AUSTIN, 1911, p. 89) ${ }^{5}$. Como explica Dworkin (2007, p. 41), esse soberano seria "uma pessoa ou grupo cujas ordens costumam ser obedecidas e que não tenha o costume de obedecer a ninguém”.

Ressalta Ronald Dworkin (2011) que o simples positivismo, com especial afinidade ao utilitarismo, defende a atuação dos juízes de forma discricionária, na qual deverão introduzir e inovar no ordenamento jurídico com novas formas de julgamentos, de modo a solucionar as lacunas, com o raciocínio jurídico sustentado pelo argumento de que aquilo seria a provável escolha do legislativo.

No que tange a esse novo desafio teórico, enquanto outros pensadores defenderiam uma atuação discricionária do soberano, Hobbes parece atenuar a expressão positivista e adotar uma postura em que a autoridade soberana, no caso o juiz, deverá recorrer às leis de natureza. Como o autor inglês destaca na obra Leviatã, o soberano deverá atuar segundo as leis de natureza, pois sua existência se perpetua mesmo na sociedade civil ao lado da lei positiva. Na hipótese desta última silenciar, as leis naturais permitiriam a solução do caso, destacando-se que "as coisas que fazem um bom juiz, ou um bom intérprete da lei, são, em primeiro lugar, uma correta compreensão daquela lei principal de natureza a que se chama equidade" (HOBBES, 1979, p. 170).

Como ressalta Bobbio (1991, p. 117), é verificável que as leis de natureza não obrigam no estado de natureza, mas, na sociedade civil, passam a obrigar uma vez que o soberano está vinculado a sua execução na hipótese de sua violação.

Thomas Hobbes (1979, p. 163) salienta que, se determinada lei não escrita for objeto

\footnotetext{
${ }^{5}$ Nas estritas palavras do pensador: "A command, then, is a signification of desire. But a command is distinguished from other significations of desire by this peculiarity: that the party to whom it is directed is liable to evil from the other, in case he comply not with the desire. Being liable to evil from you if I comply not with a wish which you signify, I am bound or obliged by your command, or I lie under a duty to obey it. If, in spite of that evil in prospect, I comply not with the wish which you signify, I am said to disobey your command, or to violate the duty which it imposes. Command and duty are, therefore, correlative terms: the meaning denoted by each being implied or supposed by the other. Or (changing the expression) wherever a duty lies; a command has been signified; and whenever a command is signified, a duty is imposed"(AUSTIN, John. Lectures of Jurisprudence: or the philosophy of positive law. 4 edition, revised and edited by Robert Campbell. Vol. 1. London and Manchester: Sherratt \& Hughes, 1911, p. 89).
} 
de observância por todas as províncias pertencentes a dado domínio e delas não resultar qualquer manifestação de iniquidade, não é possível dizer que se trata de uma lei positiva, mas de uma lei de natureza que guarda igual obrigatoriedade para todos os indivíduos.

$\mathrm{Na}$ verdade, considerando as bases da teoria do direito, Hobbes parece legitimar os usos e costumes como fontes secundárias de direitos; porém, ainda assim ocorrerá uma dependência quanto ao reconhecimento pela autoridade soberana. Em outros termos, diante da ausência da expressão da lei positiva, a manifesta observância entre os indivíduos de determinada disposição não escrita passa a ser meio de solução de determinado conflito ${ }^{6}$.

Contudo, o filósofo inglês ainda reconhece que a interpretação da lei dependerá da sentença do juiz nomeado pelo soberano para apreciação do conflito. Nas estritas palavras de Hobbes (1979, p. 167), “interpretação da lei de natureza é a sentença do juiz constituído pela autoridade soberana, para ouvir e determinar as controvérsias que dela dependem, e consiste na aplicação da lei ao caso em questão". Desse modo, ainda que seja utilizado o recurso da lei de natureza, não há dúvida de que o conteúdo expresso pela interpretação do juiz é o elemento definidor da controvérsia e se assemelha à atuação discricionária da autoridade jurisdicional, como trazida por outros autores positivistas. Afinal, será a interpretação do juiz o definidor do conteúdo da lei natural.

Como deduz Bobbio (1991, p. 119), é possível entender que o soberano, na figura do legislador, tolhe de qualquer significado próprio a lei de natureza no momento em que edita leis positivas. Do mesmo modo, o juiz priva a lei de natureza de qualquer significado inerente no momento em que aprecia casos não abrangidos pelas expressões normativas advindas do poder legislativo. Portanto, demonstra-se um poder da autoridade legitimada na definição do significado da lei natural e, consequentemente, das obrigações que serão impostas ao indivíduo, aproximando Hobbes dos autores positivistas que defendem a sujeição do indivíduo à autoridade, mesmo quando esta tem que exercer seu poder de discricionariedade para a solução de determinada controvérsia.

Nesse sentido, é possível observar elementos para a associação da teoria política de Hobbes à teoria do positivismo jurídico, com o reconhecimento da obediência à autoridade soberana, ao mesmo modo que Austin, inclusive, atribuindo poder definidor dos preceitos a

\footnotetext{
${ }^{6}$ É interessante que essa compreensão que indicaria, em uma primeira análise, um recurso ao direito natural, reforça o caráter positivista do autor e é uma compreensão ainda expressa por instrumentos normativos da contemporaneidade. Diante da omissão legal, o próprio Decreto-lei 4657/1942, denominada lei de introdução às normas do Direito Brasileiro, em seu art. $4^{\circ}$, dispõe que "o juiz decidirá o caso de acordo com a analogia, os costumes e os princípios gerais de direito". Cf. BRASIL. Decreto-lei $n^{\circ} 4.657$, de 4 de setembro de 1942. Lei de Introdução às normas do Direito Brasileiro. Disponível em: <http://www.planalto.gov.br/ccivil_03/decreto-lei/Del4657compilado.htm>. Acesso em: 08 jan. 2017.
} 
serem observados nas obrigações jurídicas decorrentes da ordem vigente. Sua teoria é caracterizada, no sentido expresso por Norberto Bobbio, por um positivismo moderado, pois ainda que preceitue a obediência absoluta à lei e ao seu comando, ela visa uma finalidade específica justificadora da origem do Estado Soberano e de sua manutenção para o perfazimento da paz e da preservação do ser humano.

\section{CONCLUSÃO}

É notável na obra de Thomas Hobbes a existência de inúmeras particularidades que dificultam a caracterização exegética e sumária em uma corrente da teoria política ou jurídica, seja o jusnaturalismo seja o positivismo. Porém, o estudo detalhado dos institutos componentes de seu pensamento viabiliza a verificação de uma forma teórica preponderante e que o aproxima de autores como John Austin e Herbert L. A. Hart.

A leitura prudencial de suas leis de natureza fortalece a interpretação adepta da perspectiva do positivismo jurídico, uma vez que não são propriamente obrigações morais vigentes e de execução forçada pelos indivíduos, mas preceitos que orientam racionalmente a ação visando determinado fim, ou seja, a autopreservação e, consequentemente, a obtenção da paz.

Dessas finalidades balizadas pelas leis de natureza, é possível a viabilização de uma argumentação lógica justificadora da origem e da manutenção do Estado Soberano, marcado pela primazia das leis positivas. Destaca-se que o dever inerente de sujeição dos súditos ao soberano aproxima Hobbes do positivismo jurídico de John Austin e releva as bases legitimadoras e de validade da ordem do direito positivo, como também realiza Herbert L. A. Hart com suas regras secundárias.

A força obrigacional das leis positivas em detrimento das leis de natureza revela traços do positivismo jurídico. Aquelas são as únicas que expressam o elemento coercitivo e, por consequência, compõem o conjunto de regras revistas de normatividade e estritamente jurídicas.

A autoridade soberana hobbesiana é a responsável pela edição de leis, sendo que estas não podem ser avaliadas como justas ou injustas, porque a justiça está atrelada ao cumprimento dos pactos e à atuação legitimada de determinada autoridade com poder para tal expressão. Logo, mais uma vez a obra de Hobbes se aproxima do positivismo jurídico pelo fato de que o Soberano não está submetido às leis civis e sua atuação não poderá ser considerada injusta.

Além disso, Hobbes destaca que a atuação da autoridade soberana poderá ser 
considerada iníqua caso seja contrária às leis de natureza; entretanto, a questão aí se relaciona à finalidade racionalmente visada por tais preceitos prudenciais. A autoridade soberana tem o dever de buscar o cumprimento das leis de natureza, enquanto preceito prudencial.

Ainda que a busca pelo cumprimento dos preceitos das leis de natureza seja devida ao soberano, Hobbes evidencia que será esta autoridade - e o direito positivo por ela emanado - a definidora do conteúdo a ser considerado. Por exemplo, ainda que o roubo e o assassinato sejam "proibidos" pela lei de natureza, serão as leis civis as responsáveis pela definição de seu conteúdo e das condutas enquadradas em tais tipos.

Na hipótese de ausência de abrangência da lei civil sobre determinado caso, isto é, de lacuna normativa, o soberano deverá apreciar em conformidade com as leis de natureza. Contudo, como já destacado, seja na figura do legislador como também do juiz, o soberano tolhe a lei de natureza de um significado normativo inerente e é ele o definidor de sua real abrangência.

Portanto, as leis naturais não podem ser aplicadas ao fato em concreto caso não sejam previstas ou sem que sejam interpretadas, e cabe ao soberano fazer "vigorar" as leis de natureza e a definição de seu conteúdo especificamente. Essa interpretação fortalece a concepção positivista que permite à autoridade a atuação discricionária do que será o direito frente à lei.

Seguindo as considerações de Norberto Bobbio acerca do positivismo jurídico, a tese hobbesiana possui proximidades ao positivismo moderado, uma vez que preceitua a obediência absoluta da lei e o comando da autoridade soberana; não obstante, almeja uma finalidade própria justificadora das origens e da perpetuação do Estado Soberano para a concretização da paz e da preservação do ser humano.

\title{
LEGAL POSITIVISM FEATURED IN THE HOBBESIAN THINKING: AN INTERPRETATION FROM CONTEMPORARY THINKERS
}

\begin{abstract}
The Hobbesian thinking influenced substantially the political and legal philosophy throughout history and still remains present, directly or indirectly, in several approaches toward the state order and its interaction with civil society. This paper aims to outline an approach of Thomas Hobbes's thought to the theory of legal positivism, by analyzing the work Leviathan or The Matter, Forme and Power of a Commonwealth Ecclesiastical and Civil (1651). Initially, we will present basic elements of law theory regarding legal positivism through the considerations of the American philosopher Ronald Dworkin and the Italian thinker Norberto Bobbio. Therefore, we will exam aspects of greater relevance of the
\end{abstract}


Hobbesian political philosophy that allow to glimpse its characterization as a positivist theory, such as the conception of the laws of nature while prudential principles, the subjection to the civil laws and to the decision-making power of sovereign authority towards the current law.

Keywords: Thomas Hobbes; Legal Positivism; Civil Society; Sovereign authority; Contemporary Thinkers.

\section{REFERÊNCIAS}

AUSTIN, John. Lectures of Jurisprudence: or the philosophy of positive law. 4 edition, revised and edited by Robert Campbell. Vol. 1. London and Manchester: Sherratt \& Hughes, 1911.

BAXTER, Hugh. Dworkin's “one-system" conception of law and morality. Boston University Law Review. Vol. 90, abr. 2010, p. 857-862. Disponível em: $<$ https://www.bu.edu/law/central/jd/organizations/journals/bulr/documents/BAXTER.pdf $>$. Acesso em: 03 jan. 2017.

BRASIL. Decreto-lei $n^{\circ} 4.657$, de 4 de setembro de 1942. Lei de Introdução às normas do Direito Brasileiro. Disponível em: $<$ http://www.planalto.gov.br/ccivil_03/decretolei/Del4657compilado.htm>. Acesso em: 08 jan. 2017.

BOBBIO, Norberto. Thomas Hobbes. Trad. Carlos Nelson Coutinho. Rio de Janeiro: Campus, 1991.

. O Positivismo Jurídico: lições de filosofia do direito. São Paulo: Ícone, 1995.

DWORKIN, Ronald. Justice for Hedgehogs. Cambridge: Harvard University Press, 2011. . Levando os Direitos a Sério. Trad. Nelson Boeira. São Paulo: Martins Fontes, 2002. 2007. . O Império do Direito. Trad. Jefferson Luiz Camargo. São Paulo: Martins Fontes,

FINN, Stephen F. Compreender Hobbes. Petrópolis: Vozes, 2010.

HART, Herbert L. A. O conceito de Direito. Lisboa: Fundação Calouste Gulbenkian, 2001.

HOBBES, Thomas. Leviatã ou matéria, forma e poder de um estado eclesiástico e civil. 2. Ed. São Paulo: Abril Cultural, 1979.

. Do Cidadão. Trad. Renato Janine Ribeiro. São Paulo: Martins Fontes, 2002.

MARCONE, Julieta. Hobbes: entre el iusnaturalismo y el iuspositivismo. Andamios. Año 1, número 2, junio, 2005, pp. 123-148. Disponível em: 
$<$ http://www.scielo.org.mx/scielo.php?script=sci arttext\&pid $=\mathrm{S} 1870-$ $\underline{00632005000300006}>$. Acesso em: 08 jan. 2017.

NEDEL, José. Thomas Hobbes: Entre o Jusnaturalismo e o Positivismo Jurídico. Veritas. vol. 38. Porto Alegre, setembro de 1993, p. 429-440.

RAWLS, John. Conferências sobre Hobbes. In: RAWLS, John. Conferências sobre a história da filosofia política. São Paulo: Martins Fontes, 2012, p. 25-109.

Trabalho recebido em 14 de fevereiro de 2019 Aceito em 06 de fevereiro de 2020 